\title{
Brand value in horizontal alliances: the case of twin-cars
}

\author{
M Esteban-Bravo* and N Lado \\ Universidad Carlos III de Madrid, Getafe, Spain
}

Rival firms often cooperate horizontally in order to share risks and achieve scale advantages in production or in their research and development projects. The output of these strategic alliances is usually sold by the individual ally company under its own brand and using its own marketing mix strategies. Marketing strategies create a cumulative effect that is reflected in brand value. Although horizontal alliances often have a significant overall impact on firm profitability, undesired brand value dilution is a worrisome possibility for the partners and therefore a relevant subject of study. In this paper, we consider brand value to be the economic added value of a brand, and propose two marketbased measures of brand value: (1) price premia (which are relevant for a unit sale) and (2) revenue premia (which also account for the premia in sales volume). We apply this analysis to the Spanish market for new automobiles, in which successful and long-lasting horizontal alliances have formed. Our findings suggest that, during the introduction stage of the product life cycle, horizontal allies did not charge different price premia, but that horizontal allies profit from differences in brand reputation obtained from demand side effects such as revenue premia (specifically, the impact on sales volume). Consequently, horizontal cooperation among brands does not dilute their value at the introduction stage. Furthermore, our results suggest that horizontal allies do charge different price premia during the growth stage of the product life cycle. Consequently, horizontal allies have recognized strategies that do not dilute brand value in intense competition mitigating the brand value diluting risk.

Keywords: brand value; price premia; revenue premia; automobile market; marketing

\section{Introduction}

Markets have been traditionally considered as competitive arenas for companies selling substitutive products. But competitors can simultaneously cooperate with each other in developing horizontal alliances in which the allied firms contribute similar resources in production processes or research and development $(\mathrm{R} \& \mathrm{D})$ to share risks or to enjoy economies of scale: better access to raw materials, lower risks in $\mathrm{R} \& \mathrm{D}$ projects and general gains in productivity, for example. Horizontal alliances can be found in industries ranging from consumer goods and pharmaceuticals to automobiles and air travel (Bengtsson and Kock, 2000; Luo et al, 2007; Walley, 2007). These alliances can be used to reduce transaction costs, gain access to new technologies or resources, gain access to new geographic and product markets, achieve economies of scale and scope, reduce financial risks, integrate markets and technologies, increase the rate of new product or process development, and reduce the cost or risk of $\mathrm{R} \& \mathrm{D}$ (Harbison and Perkar, 1995; Freidheim 1999; Luo et al, 2007). Horizontal alliances where partners all cooperate in production or/and development but independently market their products are common in numerous industries.

- A case in point is Ford, SEAT and Volkswagen collaborating to produce a multi-purpose automobile, and Ford selling it under the brand name Ford Galaxy, SEAT selling it under the brand name SEAT Alhambra and Volkswagen under the brand name Volkswagen Sharan. Often, these products are identical (twin) products sold with minor differences to develop brand and product differentiation marketing strategies among the different manufacturers. Such cooperative alliances with competitors do not imply anticompetitive price collusion; each manufacturer can charge a price consistent with its market positioning, thereby obtaining a different market share. These alliances are widespread throughout the automobile industry and in numerous other industries, including chemicals, plastics, steel, electronics, computer peripherals and airlines services (where partners cooperate in providing ground services along with ticketing and reservations). 
- Another case of horizontal strategy is white labelling, in which a manufacturer produces a product or service that other companies (the marketers) rebrand to make it appear as if they made it (Gómez Arias and Bello-Acebrón, 2008). Quality equivalent white labels offer equivalent tangible search and experience attributes to national brands, and are indistinguishable from national brands in blind (non-branded) product test (Parker and Kim, 1997). White label strategies are extended to a broad range of product categories such as electronics, home appliances, plastics and even computers. The main example is food retailing, in which large retailers often buy products in bulk from manufacturers and put their own brand name on them, while manufacturer brand equivalents can be sold in the same sales point.

The horizontal alliance seems to be an appropriate strategy for mitigating the risk for the incumbents in a market segment or product category. The flexibility intrinsic in horizontal alliances facilitates the testing with new technologies and markets. In the car industry case, both demand uncertainty and competitive uncertainty are the catalysts that impel competitors into horizontal alliances with each other (Burgers et al, 1993). Demand uncertainty that arises from unpredictable purchasing patterns and competitive uncertainty that arises from competitive interdependence are high in the initial face of the product cycle, as in the case of a new car segment.

Horizontal alliances, however, are not without critics from the marketing perspective. Associating one brand with another involves a risk that should be addressed. The risk arises not only from possible alliance failure; some authors have suggested that brand alliances should be approached strategically for fear of confounding clients and diluting brand equity (Simonin and Ruth, 1998). If the consumer evaluation of the alliance outputs is not favourable, it may result in a failed offering but also original brand associations may suffer. Typical product reviews in the automotive press are of the type: 'It (the SEAT Alhambra) is, in all but name and standard equipment (you get more from SEAT) a Volkswagen Sharan. Unless you attach some mythical value to the VW brand you would be ga-ga to pay more for less' (Wells, 2001). The damage of blurring could exist when the consequence of the brand association with the ally brand is a gradual whittling way of the identity of the brand in the consumer minds and/or the attenuation of the uniqueness of the brand in the public mind. More research is needed to explore the brand diluting risk in this context.

From the economics of information perspective, a brand helps consumers to improve the perceived quality of a product by reducing risk and the cost of search for information. However, consumers face small informational problems when comparing different brands of the same (identical) product. The products of different horizontal allies often share common unobserved attributes since they have an almost identical design and they are produced using the same inputs, with the same workers and the same equipment in the same plant. In consequence, the outputs of such kinds of horizontal alliances can be seen as a natural experiment to examine whether brand premia may be different for brands producing almost identical products. In such cases, there are no objective reasons to believe that the unobservable quality (the brand) is different, with the considerable risk of brand value dilution. Moreover, when the horizontal alliance has been implemented as a strategy to enter a new product-market segment, it offers an interesting live experiment about brand premium evolution over the different phases of the product life cycle. The methodology proposed here can help to answer such questions.

\subsection{Measuring the brand value impact of horizontal alliances}

The concept of brand value has long been an issue in marketing theory; yet there is still no consensus about the underlying elements for its measurement. Many researchers have considered brand value from a psychological perspective on the assumption that customer mindset constructs are precursors of observable market behaviour (see, eg, Keller, 1993; Aaker, 1996; Agarwal and Rao, 1996; Feldwick, 1996; Ambler and Barwise, 1998; Ailawadi et al, 2003; Keller, 2003; Keller and Lehmann, 2003). Given the pressure on marketing managers to justify their spending, the financial measurement of brand value has become a critical issue (Rust et al, 2004). In this paper, therefore, we consider brand value in terms of economic premium in the marketplace.

Price premium has been used as an outcome measure of brand value. Baltas and Saridakis $(2009,2010)$ implement a hedonic model to study price premia as indicators of brand equity in the car market. But price premium alone cannot explain all the trade-offs between brand value determinants, because price can reflect the product's strategic positioning in the market, rather than the cumulative success of previous marketing strategies. For this reason, this paper extends those works - proposing both price and revenue premium measures to study the effects of strategic alliances on brand values. We propose the use of revenue premia, measured as the brand dummy coefficients from a regression of $\log$ revenues (log of sales multiplied by prices) on product attributes, brands and seasonal time dummies. Then we obtain a revenue premia measure that subtracts the influence of product differentiation (ie, the differential effect of physical attributes on revenues). 


\subsection{The twin-car industry case}

We apply the insights of this brand value analysis to the multi purpose vehicle (MPV) market in Spain. As mentioned before, over the past two decades, independent carmakers have collaborated by forming long-lasting strategic horizontal alliances to develop and produce common vehicles, while taking advantage of economies of scale. These vehicles, called twin cars, are sold as separate models of different brands. In Europe, the production of twin cars was first developed during the 1990s as a strategy for many car producers to enter the MPV segment. Twin cars share common observed (search) and unobserved (experience and credence) attributes, as they are produced jointly in the same plant, using the same inputs, with the same workers and the same equipment. Twin cars are designed almost identically, but different versions of different brands of the same twin car may have distinctive observed attributes, which can be used to differentiate the products produced by different carmakers. The automobile sector adopts a hierarchical brand architecture that consists of a shared parent brand name, a shared model name and a unique version component. In the case of twin cars, we found that different parent brands participate in a horizontal alliance. The result of this alliance is a new model of car with an identical design. As mentioned, Ford, SEAT and Volkswagen, for example, have engaged in an alliance for the development of the MPV car since 1995. This new car is sold by each parent brand under different model brands: Galaxy, Alhambra and Sharan. These three automobile manufacturers have identical base production costs, as their vehicles are produced in the same factory; their revenue premia, therefore, is a good proxy of returns premia. More recently, Ford and Fiat, on the one side, and Nissan and Suzuki, on the other, signed agreements to co-operate on the joint development and production of twin cars models Ka, 500, Pixo and Alto for the introduction into the very small car segment. Similar examples can be found in the compact crossover segment, with Mitsubishi Outlander, Citroën C-Crosser and Peugeot 4007.

Furthermore, when computing revenue premium, only transaction prices will reflect consumers' valuation of the brand names. As in many cases panel data contain only information regarding list prices, we present a modified stochastic frontier approach to control for the brand value of uncontrolled discounts. This is the case of the MPV market at hand particularly in which there are dealers' discounts (but there were no manufacturers' discounts during the period we studied). We estimate average discounts for each version of each car model using a stochastic frontier model. This model is a regression model of $\log$ revenues (log of sales multiplied by prices) on product attributes, brands and seasonal time dummies, in which an additional non-negative random shock is added to incorporate dealers' discount effects. Therefore, this type of models has two sources of 'noise' or error terms: one that is two-side normally distributed and another one that is one-side non-negative normally distributed. The first one is not directly attributable to revenues, accounting for uncertainty in the frontier model; but the second error part is assumed to be non-negative, representing a measure of deviation from the ordinary regression model.

Our results suggest that in the introduction stage of the product life cycle of MPV market, the price premia for all the brands allied do not differ significantly, even though their price premia differ in other market segments. In particular, we test if there are, in general, differences in price premia for different carmakers in other segments, such as the utilitarian and compact segments of the Spanish automobile market. Our findings suggest that, in general, price premia differ across carmakers. Although allied companies do not charge a price premium for twin cars during the introduction stage of their product life cycle (which could be a positioning strategy for the MPV segment or could be caused by myopic managerial expectations about customers' brand mindset), they still benefit from the revenue premium. In the MPV market, we find that revenue premia are significantly different for brands of twin cars - even for those brands of twin cars with a similar range of price premium, implying that horizontal alliances do not dilute brand value.

However, our results suggest that horizontal allies do charge different price premia during the growth stage of the product life cycle. Furthermore, during this stage, allied manufacturers have increased twin-product differentiation (eg, the differences in the second generation of twin cars Citroën-Fiat-Lancia-Peugeot are more pronounced; and the second generation of twin cars Ford-Volkswagen-SEAT shares only $80 \%$ of the attributes, keeping the remaining $20 \%$ of the characteristics brand specific), searching for reasons to differentiate prices (at least other reasons beyond perceived brand value). Horizontal allies have recognized strategies that do not dilute brand value in intense competition mitigating the brand value diluting risk.

The remainder of this paper proceeds as follows. In Section 2, we present the empirical model and the estimation methodology. Section 3 describes the data and Section 4 presents the results. In Section 5, we formulate conclusions and discuss their marketing strategic implications.

\section{Model, estimation and testing}

Hedonic regressions have become common practice for the estimation of product quality bias in price indexes, after the contribution work of Court (1939) (see also Griliches, 
1971; Gordon, 1990), and the analysis of price premium in brand value (Lado et al, 2004; Baltas and Saridakis 2009, 2010). In contrast, this paper looks at hedonic revenue premium as a measure of brand value.

Assuming that some of the attributes are observable and others not, the revenue value can be broken down into two components and we get that $\log \left\{p_{j} q_{j}\right\}=\sum_{i \in I} \alpha_{i} x_{i j}+\beta b_{j}$, where $p_{j}$ is the observed price of product $j ; q_{j}$ is the quantity consumed of product $j, I$ is the set of observable attributes and $b_{j}$ is the brand value (measuring the value of unobservable attributes). In other words, hedonic revenue premium is a regression equation of the observable attributes of a product and its brand value. In this paper, we test if the coefficients of brand dummies associated with the same twin car are statistically identical; that is, whether revenue premia are similar for the companies involved in the horizontal alliance. In particular, we examine revenue premia in the MPV Spanish automobile market. A carmaker brand sells a variety of versions of a single model. Our basic units of observations are car versions. Version $i(i=1, \ldots, I)$ in period $t(t=1, \ldots, T)$ is defined by a set of observable characteristics, described by a vector of attributes $X_{i t}$. We study differences in revenue premia defined as differences in revenue because of the brand. We model the revenue premium by a linear regression with panel data,

$$
\log R_{i t}=\alpha+\gamma^{\prime} X_{i t}+\delta^{\prime} d_{t}+\beta^{\prime} b_{i}+\varepsilon_{i t},
$$

where $\log R_{i t}$ is the logarithmic transformation of revenue (the transaction price times the quantity sold); $d_{t}$ is a monthly dummy controlling for changes in nominal prices; $b_{i}$ is a brand dummy capturing the brand value, and $\varepsilon_{i t}$ are independent random shocks normally distributed $N\left(0, \sigma_{\varepsilon}^{2}\right)$ and independent from the regressors. To avoid multicollinearity, we omit one brand category (the benchmark) for each dummy set. The estimates of parameters associated with the brand dummies $\beta$ describe the relationship between revenue premium and brand value in differences with respect to the omitted brand. We study the existence of differences in revenue premia for those brands producing the same twin car by testing the identity of coefficients associated with their associated brand dummies using a likelihood ratio (LR) test. The LR test is a statistical test that compares the log likelihood of model (2) and a simpler nested model in which the coefficients associated with their respective brand dummies are equal; that is $L R=2(\ln L 1-\ln L 2)$, where $\ln L 1$ is the maximum value of the likelihood of the data without the additional assumption and $\ln L 2$ is the maximum value of the likelihood when the parameters are constrained. Under the null hypothesis, the LR statistic asymptotically follows a $\chi_{k}^{2}$ distribution, where $k$ is equal to the number of constraints.

There is a major issue related to hedonic revenue analysis: often there are no systematic and complete records on dealer discounts or on transaction prices. Instead, in many cases panel data contain only information regarding list prices. To overcome this problem, we estimate average discounts using a stochastic frontier model. The stochastic frontier production function was independently proposed by Aigner et al (1977), Meeusen and van den Broeck (1977) and Battese and Corra (1977). Battese and Coelli (1995) proposed a stochastic frontier production frontier for panel data. Frontier regression models seek to explain frontier behaviour rather than average behaviour as in ordinary regression models. Such a model may also be called a ceiling model as it lies above all the observations. Here we use a stochastic frontier model of the logarithmic transformation of listed prices $p_{i j}$, the dependence variable, modelled as a lineal relationship of the multiple independent variables $\left(X_{i t}, d_{t}, b_{i}\right.$ for each version $i=1, \ldots, I$ and each period $t=1, \ldots, T)$ plus an error term composed of two parts: the first error part is normally distributed with mean zero, accounting for uncertainty in the frontier model; and the second error part is non-negative, representing a measure of deviation from the ordinary regression model and therefore the discounts from the listed prices. In other words,

$$
\log p_{i t}=\alpha+\gamma^{\prime} X_{i t}+\delta^{\prime} d_{t}+\beta^{\prime} b_{i}+\varepsilon_{i t}+u_{i},
$$

where $\varepsilon_{i t}$ are independent random shocks normally distributed $N\left(0, \sigma_{\varepsilon}^{2}\right)$ and independent from the regressors, and $u_{i}$ are non-negative shocks so that $E\left[u_{i}\right]>0$. This modelling separates the impact of factors that cannot be controlled $\left(\varepsilon_{i t}\right.$ exogenous shocks) and a one-sided nonnegative error term $u_{i}$ representing a function of the stochastic discounts of car dealers. We consider that $u_{i}$ is time-invariant for all period $t$, since auto industry experts at the Instituto de Estudios de Automoción (IEA) and the Autopista Magazine confirm that discount percentages applied to listed prices are always positive and relatively stable over the sample period for each car version. This model cannot be consistently estimated by standard panel data methods. However, assuming $u_{i}$ is a truncated normally distributed variable (ie, $u_{i}=\left|U_{i}\right|$ and $U_{i}$ are assumed to be independently distributed normal $N\left(\mu, \sigma_{u}^{2}\right)$ ), the maximum likelihood estimators for the model (2) can be computed by standard numerical methods (see, eg, Kumbhakar and Lovell, 2000).

Equation (2) shows the relationship between observed listed prices $p_{i j}$ and actual transaction prices $P_{i t}$. The $\log$ of the transaction prices $P_{i t}$ is given by the difference between the $\log$ of the listed prices $p_{i j}$ and an error $u_{i}$; that is, $\log P_{i t}=\log p_{i t}-u_{i}$; then,

$$
\log \frac{p_{i t}}{P_{i t}}=u_{i}
$$

Using the estimates of $u_{i}$, we can compute the discount percentage applied to listed prices for each car version $i$. Let $x_{i}$ be the per cent discount on listed prices $p_{i t}$; that is, 
$P_{i t}=\left(1-x_{i}\right) p_{i t}$. Then, $P_{i t} / p_{i t}=\left(1-x_{i}\right)$, and using (3), $\left(1-x_{i}\right)=1 / \exp \left(u_{i}\right)$. As a consequence, the percentage of discount $x_{i}$ is defined as

$$
x_{i}=1-\left(\frac{1}{\exp u_{i}}\right) .
$$

\section{Data}

The original database was provided by the Spanish IEA. The IEA collects data for 48 parent brands, 300 model brands and more than 5000 versions, representing most of the entire population of automobiles sold in the Spanish market. In this study, we used monthly data from July 1997 to May 2000, the introduction stage of the MPV life cycle, and January 2005 to December 2007, the growth stage of the MPV life cycle.

The data set from July 1997 to May 2000 includes listed prices, sales and 17 relevant characteristics for brand models at the version level (variants of the original) in the MPV, utilitarian and compact categories. The MPV category comprises 155 versions of 13 brand models (and 13 parent brands, one for each model). The number of observations of this panel data is 2677. Among these 13 brand models are two sets of twin cars. The first twin set includes Citroen Evasion, Fiat Ulysses, Lancia Zeta and Peugeot 806; and the second includes Ford Galaxy, SEAT Alhambra and Volkswagen Sharan. Other models (non-twin models) included in the database are Mazda MPV, Mitsubishi Space-wagon, Nissan Serena, Opel Sintra and Renault Espace. On average, an MPV car in our sample costs approximately about $\$ 42819$ and the average sales growth rate is $0.7 \%$ per year. The panel data of the utilitarian category contain 5545 observations and information on 460 versions of 10 brand models (and 10 parent brands). On average, a utilitarian car in our sample costs approximately $\$ 18669$ and the monthly sales are about 1975 car units. The panel data of the compact category include 642 versions of 12 brand models (11 parent brands and 6402 observations). On average, a compact car in our sample costs approximately \$25791 and the monthly sales are about 1629 car units. Given the fact that in the three car categories, all the parent brands, with the exception of the one in the compact category, have a unique brand model, it is impossible to separate the value of the parent brand from the model brand value. For this reason, we continue our analysis on brand cars in general.

The matrix $X_{i t}$ is defined by 17 observable characteristics for each car version $i$ and each period $t$, which can be categorized into two different types: the continuous variables of engine power (h.p.), top speed $(\mathrm{km} / \mathrm{h})$, acceleration (sec. in $0-100 \mathrm{~km} / \mathrm{h}$ ), volume $\left(\mathrm{m}^{3}\right)$, fuel consumption (liters $/ 100 \mathrm{~km}$ ), cylinder capacity (c.c.); and the discrete dummy variables of air-conditioning, automatic climate, front power windows, rear power windows, driver airbag, passenger airbag, ABS brakes, remote lock, on-board computer, alloy wheels and turbotaking values of 1 if this attribute is included in the standard equipment, and 0 otherwise. As the descriptive statistics for the diesel and gasoline automobiles are relatively different, we include a dummy for diesel engines that aims to capture the difference. Furthermore, given that our sample period coincides with the diffusion of the direct injection technology - the so-called TDIsamong the turbo-diesel models, we also introduce a dummy that accounts for this fact.

The data set from January 2005 to December 2007 includes listed prices, sales and 17 characteristics for brand models at the version level (variants of the original) in the MPV market of automobiles sold in the Spanish market from January 2005 to December 2007. Six of these characteristics were present in all the versions in this period, resulting not relevant for the analysis. The MPV category comprises 166 versions of 12 brand models (and 12 parent brands). The number of observations of this panel data is 5868. Among these 12 brand models are two sets of twin cars. The first twin set includes Citroen C8, Fiat Ulysses, Lancia Phedra and Peugeot 807; and the second includes Ford Galaxy, SEAT Alhambra and Volkswagen Sharan. Other models (non-twin models) included in the database are Chrysler Voyager, Chrysler Grand Voyager, Hyundai H-1, Kia Carnival, Renault Espace, Renault Gran Espace and Ssangyong Rodius. On average, an MPV car in our sample costs approximately $\$ 45610$ and the average sales growth rate is $6.7 \%$ per year. We do not consider other categories for this period of time, because we observe a different price premium for each parent brand, and therefore, we can conclude that there is a differentiation strategy among manufactures as in other categories in which there are not horizontal alliances.

The matrix $X_{i t}$ is defined by 17 observable characteristics for each car version $i$ and each period $t$, which can be categorized into two different types: the continuous variables of engine power (h.p.), top speed $(\mathrm{km} / \mathrm{h}$ ), volume $\left(\mathrm{m}^{3}\right)$, cylinder capacity (c.c.); and the discrete dummy variables of type of compressor, alloy wheels, ABS brakes, stability control system, information technology system, passenger airbag, remote lock - taking values of 1 if this attribute is included in the standard equipment, and 0 otherwise. Note that in this case, there are more redundant or insignificant attributes than before because of the technological advances of the industry.

Note that this is a rich database, particularly suitable for studying the interrelationships between product differentiation and horizontal alliances. Sullivan (1998) considered twin cars in the US second-hand market, but from the company's strategic perspective, the new automobile market offers the convenience of being able to study horizontal alliances. 


\section{Results}

Our first step is to calculate the average percentage discount from the listed price. Then we estimate the parameters of the stochastic frontier model (2). For data corresponding to the first time period, Table 1 reports the Wald test showing the global significance of the explanatory variables in model (2) and the goodness of fit of model (2). Table 1 also reports the brand estimates of model (2) as discussed in Section 2; in the first column, we report the coefficient estimates associated with brand dummies and the standard errors are reported in the second column. The estimated constant conveys the price premia of the reference brand, Renault (the benchmark category because Renault is the brand leader in 1997).

Table 1 Parameter estimates for MPV segment ${ }^{\dagger}$ (first period). Dependent variable: $\log ($ Price $)$

\begin{tabular}{|c|c|c|}
\hline Variables & Coefficient & Standard error \\
\hline \multicolumn{3}{|c|}{ Coefficients of brand dummies } \\
\hline Citroen & $0.047 * *$ & 0.011 \\
\hline Fiat & $0.050 * *$ & 0.0124 \\
\hline Lancia & $0.079 * *$ & 0.011 \\
\hline Peugeot & $0.032 * *$ & 0.011 \\
\hline Ford & $0.042 * *$ & 0.012 \\
\hline SEAT & $0.030 * *$ & 0.011 \\
\hline Volkswagen & $0.049 * *$ & 0.013 \\
\hline Mazda & $0.16^{* *}$ & 0.016 \\
\hline Mitsubishi & $0.19 * *$ & 0.020 \\
\hline Opel & 0.015 & 0.018 \\
\hline Nissan & $0.16^{* *}$ & 0.027 \\
\hline Constant & $10.03 * *$ & 0.442 \\
\hline \multicolumn{3}{|c|}{ Coefficients of car characteristics } \\
\hline Engine power & $0.141 * *$ & 0.05 \\
\hline Speed & $0.014 * *$ & 0.06 \\
\hline Acceleration & $0.007 * *$ & 0.02 \\
\hline Volume & $0.242 * *$ & 0.03 \\
\hline Consumption & $0.269^{* *}$ & 0.07 \\
\hline Cylinder capacity & $0.397 * *$ & 0.07 \\
\hline Air conditioning & $0.039 * *$ & 0.00 \\
\hline Automatic climate & $0.033 * *$ & 0.00 \\
\hline Front power windows & $0.022 * *$ & 0.01 \\
\hline Rear power windows & $0.007 * *$ & 0.00 \\
\hline Driver airbag & $0.015^{* *}$ & 0.01 \\
\hline Passenger airbag & $0.003 * *$ & 0.00 \\
\hline ABS brakes & $0.005^{* *}$ & 0.00 \\
\hline Remote lock & $0.002 * *$ & 0.00 \\
\hline Information technology & $0.010 * *$ & 0.00 \\
\hline Alloy wheels & $0.040^{* *}$ & 0.00 \\
\hline Turbo & $0.055^{* *}$ & 0.01 \\
\hline Turbo diesel & $0.185^{* *}$ & 0.03 \\
\hline Petrol & $0.030 * *$ & 0.05 \\
\hline Wald test $\chi_{71}^{2}$ & 9458.09 & \\
\hline Prob $>\chi_{71}^{2}$ & 0.00 & \\
\hline Log likelihood & 6494.3 & \\
\hline
\end{tabular}

$*$ and $* *$ significant at $10 \%$ and $5 \%$ level, respectively.

†nly brand dummies are shown.
All the coefficient estimates must be interpreted in terms of percent change, as model (2) considers a logarithmic transformation of price. The Wald test shows the global significance of the explanatory variables in model (2) and the goodness of fit of model (2). All brand dummies but Opel are significantly different from zero, meaning that brands have significantly different price premia to the reference brand, Renault, the largest difference being -0.19 between Renault and Mitsubishi. As this estimate is negative, we can conclude that the average price premium of Mitsubishi is $19 \%$ lower than the average price premium of Renault. We also find a significantly large difference in the average price premia between Renault and Mazda and Renault and Nissan: -0.16 . For these brands of twin cars, the differences in the average price premia are significantly different from zero, but smaller. All the signs of price premia estimates for Twin 1 (Citroen, Fiat, Peugeot and Lancia) are negative, with the exception of Lancia. This finding implies that, in terms of percentage change, the average price premia of Citroen, Fiat and Peugeot are below the reference brand, Renault. In contrast, the average price premium of Lancia is higher than Renault's. This is an indication that price premia between brands of Twin 1 are significantly different.

Table 1 also reports the brand estimates and car attributes estimates of model (2) as discussed in Section 2. All the coefficient estimates must be interpreted in terms of per cent change, as model (2) considers a logarithmic transformation of price. The Wald test shows the global significance of the explanatory variables in model (2) and the goodness of fit of model (2). All car attributes estimates are significantly different from zero, meaning that car attributes have a significant effect on price premia, with the performance-related attributes (engine power, speed and cylinder capacity, turbo and turbo diesel) being those with higher positive effect. The coefficient of volume is also significantly high and positive, as expected in this type of cars. Also, features related to comfort and luxury (air-conditioning, automatic climate, front power windows, rear power windows, alloy wheels) have significant positive coefficients but not high ones. The coefficient of fuel consumption has an unexpected significant positive effect on price premia, but note that in this type of cars, engine power is highly correlated to fuel consumption and European MPVs are generally powered by large engines with high fuel consumption.

Next, we formally test whether all the coefficients associated to brand dummies are identical (ie, all brands have the same price premia) using an LR test. The LR statistics takes the value 96.19 and the null hypothesis is rejected at a $95 \%$ significance level. Table 2 reports the LR test for the null hypothesis of no differences in price premia on carmakers producing the same twin. When the null hypothesis is rejected, there is an indication that price premia are not necessarily equal for the considered 
Table 2 The average discounts for different brands in the MPV category

\begin{tabular}{lc}
\hline Brand & Average \\
\hline Citroen & 9.5 \\
Fiat & 6.3 \\
Lancia & 3.7 \\
Peugeot & 7.9 \\
Ford & 5.1 \\
SEAT & 8.5 \\
Volkswagen & 4.9 \\
Mazda & 3.9 \\
Mitsubishi & 9.1 \\
Opel & 1.8 \\
Nissan & 5.0 \\
Renault & 11.7 \\
\hline
\end{tabular}

brands. We observe that the price premia of brands that do not belong to a twin car (Mazda, Mitsubishi, Opel, Nissan) are significantly different. Furthermore, the LR statistics related to Twin 1 (Citroen, Fiat, Lancia, Peugeout) indicates that the price premia of these brands are also significantly different. A close analysis of these brands is reported in Table 3. The differences on price premium of Twin 1 are given by the pair Lancia and Fiat, while the remaining brands have similar price premia (see Table 3).

The results suggest that allied firms producing the same twin adopt identical price positioning (once attribute variations are discounted), suggesting that they position their product as identical in terms of economic value for the customer. Clearly, if customers' sales responses are not identical for these twin cars this must be due to different mind-set perceptions of the brand value that were uncounted for by the producers.

It is also relevant to study whether or not companies involved in the horizontal alliance were self-selected because they already lack price-premium differences. One possible explanation is that only firms with similar price premium value involve themselves in horizontal alliances. To test this hypothesis, we have estimated model (2) for other car categories (such as utilitarian and compact cars) in which there is no production of twin cars (maintaining Renault as the omitted group). We found differences in price premia in utilitarian and compact cars among carmakers, even those that produce the same twin car in the MPV category. Therefore, in general, the brands involved in this type of alliances have price-premium differences in other car categories in which there are no production of twin cars.

Our next step was to consider Equation (4) to calculate the average percentage discount from the listed price, and we compute the sample mean of $\left\{x_{i}\right\}$. Let $\hat{x}_{i}$ be the estimate of discounts applied to the listed prices of each car version $i$. Table 4 shows the average discounts for each brand, computed by averaging the estimates $\left\{\hat{x}_{i}\right\}$ of the subsample
Table 3 The LR test for the null hypothesis of no differences in price premia

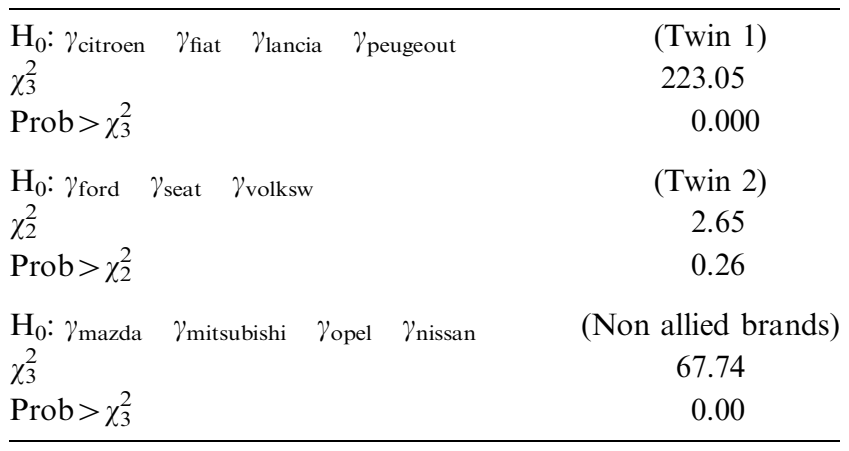

Table 4 The LR test for the null hypothesis of no differences in price premia in Twin 1

\begin{tabular}{lr}
\hline $\mathrm{H}_{0}: \gamma_{\text {fiat }}=\gamma_{\text {lancia }}$ & \\
$\chi_{2}^{2}$ & 135.62 \\
Prob $>\chi_{2}^{2}$ & 0.00 \\
$\mathrm{H}_{0}: \gamma_{\text {citroen }}=\gamma_{\text {peugeout }}$ & \\
$\chi_{2}^{2}$ & 2.31 \\
Prob $>\chi_{2}^{2}$ & 0.12 \\
\hline
\end{tabular}

given by all versions $i$ of each brand. We observe that Renault dealers offer the largest average discountapproximately $11 \%$. We also observe differences in the pattern of average discounts for Twin 1. Citroen offers the second highest discount, at an average of 9\%; Fiat and Peugeot dealer discounts average $6 \%$ and $7 \%$, respectively; and Lancia, at an average of $3 \%$, has the second lowest discount. This is an indication that the discount policies for retailers of the allied brands of Twin 1 are also significantly different, and that listed prices cannot be used to estimate brand value. The sample mean of the sequence $\left\{\hat{x}_{i}\right\}$ is the percentage of average discount for the MPV category, 0.10 ; in other words, we estimate that consumers are able to obtain discounts up to an average of $10 \%$. According to the opinion of industry experts, this valuation seems to be reasonable. In the Spanish automobile market, dealers are willing to bargain on their profit margin, which often ranges from 15 to $25 \%$, depending on the brand and type of vehicle. For the period considered here, however, discounts and promotions were lower in the MPV category. Also MPVs can be considered a luxury product, and therefore the target potential customer will be affluent families whose decision making is less influenced by discounts. Furthermore, manufacturers did not offer rebates or any other types of promotional discounts during this period.

We then focus on the revenue premium in the MPV category. We consider an estimate of the revenue for each car version $i$ and each period $t, R_{i t}=\left(1-\hat{x}_{i}\right) p_{i t} V_{i t}$, where $\left\{\hat{x}_{i}\right\}$ is the estimate of discounts applied to the listed prices 
Table 5 Estimated results for MPV segment ${ }^{\dagger}$. Dependent variable: $\log ($ Revenue $)$

\begin{tabular}{lcc}
\hline Variables & Coefficient & Standard error \\
\hline Citroen & $0.73^{* *}$ & 0.07 \\
Fiat & $1.58^{* *}$ & 0.09 \\
Lancia & $2.63^{* *}$ & 0.09 \\
Peugeot & $0.24^{* *}$ & 0.07 \\
Ford & $0.94^{* *}$ & 0.09 \\
SEAT & $0.61^{* *}$ & 0.09 \\
Volkswagen & $1.25^{* *}$ & 0.10 \\
Mazda & $3.52^{* *}$ & 0.13 \\
Mitsubishi & $1.00^{* *}$ & 0.13 \\
Opel & $1.43^{* *}$ & 0.10 \\
Nissan & 0.099 & 0.13 \\
Constant & 2.39 & 4.70 \\
F(71 2521) & & \\
Prob $>$ F(71 2521) & 137.98 & \\
$R$ square & 0.00 & \\
\hline
\end{tabular}

$*$ and $* *$ significant at $10 \%$ and $5 \%$ levels, respectively.

†nly brand dummies are shown.

of each car version $i$, and $V_{i t}$ are the sales at time $t$. Least squares estimation of model (1) will provide consistent estimates of the coefficients associated with brand dummies. The estimated constant represents the revenue premia of the reference brand, Renault. All brand dummies but Nissan are significant (see Table 3). Their significance in the revenue response model (3) implies that there is evidence of differences in revenue premia in the MPV category. We also found that the LR statistics reject equality of revenue premia of brands in both, Twin 1 and Twin 2. Therefore, we found differences in revenue premia among carmakers, even those that produce the same twin car in the MPV category. As a consequence, this indicates that brand value does have an impact on the firms' revenues, even though, as a result of horizontal alliances, carmakers do not charge price premia to their customers (Table 5).

Next, Table 6 presents the estimated of model (2) for data between 2005 and 2007. The Wald test shows the global significance of the explanatory variables in model (2) and the goodness of fit of model (2). All brand dummies are significantly different from zero and negative, meaning that brands have significantly different and lower price premia than the reference brand, Renault. The largest differences with the reference brand are between Renault and Korean manufacturers (Ssanyong, Hyundai and Kia), with the average price premium of Korean manufacturers being between 25 and $36 \%$ lower than the average price premium of Renault. We also find a significantly small difference in the average price premia between Renault and Ford: -0.023 . We also observe that the difference in the average price premia between Renault and those brands of
Table 6 Parameter estimates for MPV segment ${ }^{\dagger}$ (second period). Dependent variable: $\log ($ Price $)$

\begin{tabular}{|c|c|c|}
\hline Variables & Coefficient & Standard error \\
\hline \multicolumn{3}{|c|}{ Coefficients of brand dummies } \\
\hline Chrysler & $0.077 * *$ & 0.006 \\
\hline Citroen & $0.087 * *$ & 0.006 \\
\hline Fiat & $0.072 * *$ & 0.007 \\
\hline Ford & $0.023 * *$ & 0.005 \\
\hline Hyundai & $0.275^{* *}$ & 0.008 \\
\hline Kia & $0.265 * *$ & 0.006 \\
\hline Lancia & $0.042 * *$ & 0.005 \\
\hline Peugeot & $0.089 * *$ & 0.004 \\
\hline SEAT & $0.169 * *$ & 0.003 \\
\hline Ssanyong & $0.361 * *$ & 0.008 \\
\hline Volkswagen & $0.066 * *$ & 0.005 \\
\hline Constant & $2.498 * *$ & 0.450 \\
\hline \multicolumn{3}{|c|}{ Coefficients of car characteristics } \\
\hline Cylinder capacity & $0.327 * *$ & 0.009 \\
\hline Engine power & $0.219 * *$ & 0.012 \\
\hline Speed & $0.104 * *$ & 0.028 \\
\hline Volume & $0.160 * *$ & 0.018 \\
\hline Compressor & $0.116^{* *}$ & 0.003 \\
\hline Alloy wheels & $0.075 * *$ & 0.003 \\
\hline ABS brakes & $0.075^{* *}$ & 0.006 \\
\hline Stability Control & $0.013 * *$ & 0.004 \\
\hline Information tech. & $0.075 * *$ & 0.004 \\
\hline Passenger airbag & $0.020 * *$ & 0.003 \\
\hline Remote lock & $0.041 * *$ & 0.007 \\
\hline Wald test $\chi_{22}^{2}$ & 35959.05 & \\
\hline Prob $>\chi_{22}^{2}$ & 0.00 & \\
\hline Log likelihood & 7529.5 & \\
\hline
\end{tabular}

$*$ and $* *$ significant at $10 \%$ and $5 \%$ level, respectively.

${ }^{\dagger}$ Only brand dummies are shown.

Twin 1 (Citroen, Fiat, Lancia, Peugeot) differ significantly among them. More significantly, this is the case for Twin 2 (Ford, SEAT, Volkswagen). This is an indication that price premia between brands of twin cars are significantly different.

All car attributes estimates are significantly different from zero, meaning that car attributes have significant effect on price premia, with the performance-related attributes (engine power, speed and cylinder capacity) being those with higher positive effect. The coefficient of volume is also significantly high and positive, as expected in this type of cars.

Finally, we formally test whether all the coefficients associated to brand dummies are identical (ie, all brands have the same price premia) using an LR test. The null hypothesis of no differences in price premia on carmakers producing the same twin is rejected for Twin 1 (Citroen, Fiat, Lancia, Peugeout) and Twin 2 (Ford, Seat, Volkswagen). Also, we observe that the price premia of brands that do not belong to a twin car are significantly different. Therefore, allied partners of twin car have reconsidered the 
marketing strategy of having identical price premia, and now they are adopting different price positioning.

Furthermore, during the growth stage of the product life cycle of MPVs, the discounts, as expected, in this category were even lower than in the introductory phase in the Spanish market because MPVs can be considered a luxury product. At the stage of growth, the market shares of the brands have achieved some stability. The discounts used in the introductory phase to encourage the purchase and develop the initial application are minimized. Moreover, in this period, the entry of Korean cars with a low price positioning neutralizes the countdown policy of the dealers of other brands.

\section{Conclusions}

Brand value is a holistic concept synthesizing the effect of competitive marketing strategies. It is commonly conceptualized as the added value with which a given brand endows a product. We adopt the firm-centered conceptualization of brand value as the residual value not explained by objectives attributes.

Researchers studying horizontal alliances, in which a partner is simultaneously a competitor, have argued that it is the most beneficial relationship between competitors (Bengtsson and Kock, 2000; Walley, 2007). These strategies implemented to mitigate the market risk of entering a new product market could leverage other kinds of risks. The high level of demand uncertainty and competitive uncertainty present in the introduction in a new productmarket are the catalysts that drive competitors into horizontal alliances with each other (Burgers et al, 1993). As Luo et al (2007) have noted, excessive competition introduces a new kind of risk that is the risk of vulnerability. Moreover, brand alliances involved a marketing risk; the risk of confounding clients and diluting brand equity. It is our understanding that almost no study has empirically investigated the brand diluting risk of horizontal alliances. Our study focuses on the impact of horizontal alliances strategies on brand value.

Our findings suggest that in the new automobile market in Spain, horizontal alliances do not dilute brand value. However, the mechanism through which the brands assert their brand value differs along the stages of product life cycle. In the early stage of the product life cycle, horizontal strategic alliances dilute the price premia of brands, but we found significant differences in brand revenue premia. The brand consumer-centered mechanism, the response of customer via volume, allows firms to see their brand value reflected. We found that allied partners are reluctant to adopt different price positioning, given that the twin products are identical. In the mature phase, partners have reconsidered this strategy and have increased the twin product differentiation. The results suggest that, to some extent, manufacturers have searched for reasons to differentiate prices (at least other reasons beyond perceived brand value). We observe that price premia differences reflect the differences in the costumers' willingness to pay for the different allied brands.

In brief, analysis using hedonic regressions was performed on data generated from two different time periods. The first period relied on data from 1997 to 2000. In this period twin cars alliance were used as a strategy to introduce in a new market segment. The partners' brands do not differentiate the products (the car designs were identical). We observe that in the initial phase of the alliance agreement, brands avoid aggressive reactions of the allies by alienating the price premium tactics. As a result, and perhaps as a strategy for competitive risk reduction, we detect that carmakers do not charge different brand premium. This trend indicates that managers tend to perceive price differentiation as a risky decision when the products are closely designed. With the exception of Lancia, they have been charging roughly the same price, and allowing their customers' mind-set brand value differences to be the basis for sales differences, and therefore for revenue premia. In addition, they used price discount as a discrimination price strategy to stimulate short-term demand reaction. The brand revenue is significantly different, indicating that volume was the factor that allows brand to benefit from the different brand reputation.

The second period analysis, based on data generated from 2005 to 2007, indicates a reversal and the price premium of the twin cars brands are now significantly different. The new flexible production systems allow the carmakers to differentiate the car aspect and design. The growth of the segment and the reduction of uncertainty about competitive reactions relaxes the competitive pressures and allows the brand to charge different price premium. The discount tactics become less interesting.

From the methodological point of view, this research makes a twofold contribution.

First, as the marketing literature postulates, there is a gap between the perceived attributes of a product by the buyers and the observed attributes by the manufacturers. In addition, there is a gap between the attributes observed by the manufacturers and measured by the researchers, since some attributes could be omitted or neglected in a research study. An attribute observed by the economic agents, such as reputation or a new technologic advantage, for example, that is common to all versions of a brand, could not be measured by the researcher. In the estimation, the value of this attribute is collected by the brand dummy coefficient. What is less clear is whether this is part of the brand premia or if it corresponds to the value of an omitted (by the researcher) attribute. For this reason it is difficult to compare the estimated coefficients of different brands. However, cars belonging to the same twin share most 
of the omitted characteristics. Thus, differences in the estimated coefficients of brand dummies may be interpreted as differences in brand premia.

Many other sectors can be considered. In particular, our methodology is very useful to study the brand value of a product marketed under different brands, or private label brands, for instance.

Second, there is another major issue related to hedonic revenue analysis: rarely are systematic and complete records on transaction prices available. To surmount this difficulty, we estimate average discounts using a stochastic frontier model.

Future research could analyse the effect of competitor alliance on the different brand levels, differentiating the impact of the alliance on the value of the parent brand and the value of the model brand. In the segment of the automobiles that we have studied, each parent brand has only one model brand. Consequently, we cannot differentiate the impact on the parent brand from the impact on the model brand name. In this paper, we focus on brand value from the managerial point of view; another potentially valuable and complementary future research stream could be the study of the impact of horizontal brand alliances on customer perceptions.

Acknowledgements - We would like to thank Miguel Aguilar for providing us with the data. We have benefitted from the useful comments and suggestions of Jose M. Vidal Sanz. The usual disclaimer applies. We acknowledge the financial support of the Spanish Ministry of Education and Science (SEJ2007 65 897/ECON).

\section{References}

Aaker DA (1996). Measuring brand equity across products and markets. Calif Mngt Rev 38(Spring): 102120.

Agarwal MK and Rao V (1996). An empirical comparison of consumer based measures of brand equity. Market Lett 7: 237247.

Aigner DJ, Lovell CAK and Schmidt P (1977). Formulation and estimation of stochastic frontier production function models. J Econom 6: 2137.

Ailawadi KL, Lehmann DR and Neslin SA (2003). Revenue premium as an outcome measure of brand equity. $J$ Marketing 67(4): 117.

Ambler T and Barwise P (1998). The trouble with brand valuation. J Brand Mngt 5: 367377.

Baltas G and Saridakis C (2009). Brand name effects, segment differences, and product characteristics: An integrated model of the car market. J Prod Brand Mgnt 18: 143151.

Baltas G and Saridakis C (2010). Measuring brand equity in the car market: A hedonic price analysis. J Opl Res Soc 61: 284293.

Battese GE and Coelli TJ (1995). A model for technical inefficiency effects in a stochastic frontier production function for panel data. Empirical Econ 20: 325332.

Battese GE and Corra GS (1977). Estimation of a production frontier model: With application to the pastoral zone of Eastern Australia. Aust J Agr Econ 21: 169179.
Bengtsson M and Kock S (2000). 'Coopetition' in business networks To cooperate and compete simultaneously. Ind Market Mngt 29: 411426.

Burgers W, Hill C and Kim C (1993). A theory of global strategic alliances: The case of the global auto industry. Strategic Mgnt J 14: 419432 .

Court A (1939). Hedonic Price Indexes with Automobile Examples. General Motors Corporation: New York.

Feldwick P (1996). What is brand equity anyway, and how do you measure it. J Market Res Soc 38(April): 85104.

Freidheim CF (1999). The battle of the alliances. Mngt Rev 88(8): 4651.

Gómez Arias JT and Bello Acebrón L (2008). Why do leading brand manufacturers supply private labels? J Bus Ind Market 23: 273278 .

Gordon R (1990). The Measurement of Durable Goods Prices. The University of Chicago Press: Chicago.

Griliches Z (1971). Hedonic price indexes revisited. In: Griliches Z (ed). Price Indexes and Quality Change. Harvard University Press: Boston, pp 315.

Harbison JR and Perkar Jr P (1995). Cross Border Alliances in the Age of Collaboration. Booz Allen \& Hamilton Inc.: McLean, Virginia.

Keller KL (1993). Conceptualizing, measuring and managing consumer based brand equity. J Marketing 57: 122.

Keller KL (2003). Understanding brands, branding and brand equity. Interact Market 5(1): 720.

Keller KL and Lehmann DR (2003). How do brands create value? Market Mngt 12(3): 2631.

Kumbhakar SC and Lovell CA (2000). Stochastic Frontier Analysis. Cambridge University Press: Cambridge.

Lado N, Licandro O and Pérez F (2004). How brand names affect the price setting of carmakers producing twin cars. Working Paper ECO No. 2004/1, Department of Economics, European University Institute.

Luo X, Rindfleisch D and Tse K (2007). Working with rivals: The impact of competitor alliances on financial performance. $J$ Marketing Res 44(1): 7383.

Meeusen W and van den Broeck J (1977). Efficiency estimation from Cobb Douglas production functions with composed error. Int Econ Rev 18: 435444.

Parker P and Kim N (1997). National brands versus private labels: An empirical study of competition, advertising and collusion. Eur Mngt J 15: 220235.

Rust RT, Ambler T, Carpenter GS, Kumar V and Srivastava RK (2004). Measuring marketing productivity: Current knowledge and future directions. $J$ Marketing 7689.

Simonin BL and Ruth JA (1998). Is a company known by the company it keeps? Assessing the spillover effects of brand alliances on consumer brand attitudes. J Marketing Res 35: 3042.

Sullivan MW (1998). How brand names affect the demand for twin automobiles. J Marketing Res 35: 154165.

Walley R (2007). Coopetition: An introduction to the subject and an agenda for research. Int Stud Mngt Organ 37(2): 1131.

Wells P (2001). Platforms: Engineering panacea, marketing disaster? J Mater Process Tech 115: 166170. 